\title{
Applications of Good Psychiatric Management for Borderline Personality Disorder: A Practical Guide
}

\author{
Chang-Hun Lee \\ Leechanghun Psychiatric Clinic, Ulsan, Korea
}

\author{
경계선 성격장애를 위한 좋은 정신과적 관리: 모든 상황에서 적용가능한 \\ 이창훈 \\ 이창훈 정신건강의학과의원
}

저 자: Lois W. Choi-Kain, John G. Gunderson 출판사: American Psychiatric Association Publishing 출간연도: 2019 (ISBN: 978-1-61537-225-6)

2019년 1월, "Father of BPD, 향년 76세로 세상을 떠나다" 라는 제목으로 기사가 발표되었다. 바로 Harvard 의과대학 의 교수이자, McLean 병원 정신과의사로서 경계선 성격장 애의 연구와 치료에 헌신했던 J.G. Gunderson의 타계 소식 이었다. Father of $\mathrm{BPD}$ (경계선 성격장애의 아버지)라는 별 명은 그에게 가장 어울리는 존경과 찬사의 의미가 담겨 있다.

그는 정교한 최첨단의 치료 대신 실용적인 의료 관리가 전 세계의 경계선 성격장애 환자들에게 절실하게 필요하다는 것을 일찍이 깨닫고, borderline personality disorder(BPD) 환자 모두에게 충분히 좋은 good-enough 치료가 전파 가능 하도록 하는 데에 평생의 노력을 기울였다. 바로 '좋은 정신과 적 관리(good psychiatric management, GPM)'가 그것이다.

GPM은 Gunderson이 집필하여 1984년 처음 소개된 이래 점진적으로 진화하였다. Paul Link가 GPM을 매뉴얼화한 가이드북이 2014년에 출판되었고, 역자가 번역한 “모든 상 황에서 적용가능한 경계선 성격장애를 위한 좋은 정신과적 관리”(2019)는 GPM을 다양한 상황에 응용하고, 또 다른 특

Address for correspondence: Chang-Hun Lee, MD

Leechanghun Psychiatric Clinic, \#401 Kolon Park Police Shopping Arcade, 241 Daegongwon-ro, Nam-gu, Ulsan 44667, Korea

Tel: +82-52-265-2051, Fax: +82-52-265-2071

E-mail: drchanghunlee@gmail.com

This is an Open Access article distributed under the terms of the Creative Commons Attribution Non-Commercial License (https://creativecommons.org/licenses/by-nc/4.0) which permits unrestricted non-commercial use, distribution, and reproduction in any medium, provided the original work is properly cited.
수치료법에 통합하여 절충적인 활용이 가능하도록 한 안내 서이다.

Donald Winnicott의 'good-enough mother'에서의 'good'이 바로 Gunderson이 지향하는 good management의 정신이다. 치료자들이 $\mathrm{BPD}$ 환자를 돌보면서 어쩔 수 없이 맞닥뜨리 는 한계를 인정하고 제한적인 방식의 관리로도 충분히 좋은 관리를 제공할 수 있다고 강조한다. 역자는 이것이 $\mathrm{BPD}$ 의 치료와 관리에 획기적 전환을 가져올 개혁적 관점이라고 생 각한다.

모두가 알다시피 경계선 성격장애는 소위 '쓰레기통 진 단', 회복이 힘든 ‘난치병'(p.17)으로 약 100 년 가까이 낙인 찍혔었다. 치료자들은 이들이 치료에 저항하고 치료진을 괴 롭힐 것이라는 두려움 때문에, $\mathrm{BPD}$ 환자들의 치료를 기피 하고 환자와 그 가족에게, 모호한 진단과 함께 복합적이고 중한 질병이라는 인상을 주며 회복된다는 기대를 낮추도록 조언한다. 치료법에 대해서 잘 모르기도 하고, $\mathrm{BPD}$ 를 위한 특수치료(변증법적 행동치료, 마음헤아리기 치료, 전이초점 치료 등)를 하는 전문가에게 의뢰하는 통로도 없기에, 장기간 의 약물치료로도 크게 호전되지 않는다는 것을 알면서도 약 물들을(항우울제, 비정형정신병약물, 벤조디아제핀 및 기분조 절제 등) 혼합하여 처방하고 있다. 그런데 정신과 환자의 다섯 명 중에 한 명이 $\mathrm{BPD}$ 환자이며 응급실 내원 환자의 $1 / 10$, 일 차의료기관 환자의 $1 / 20$ 이 $\mathrm{BPD}$ 환자이다(p.21). 그렇다면 특 히 정신과 의사가 만나는 환자의 $20 \%$ 이상을 제대로 된 지도 와 나침반, 랜턴도 없이 한밤중에 산길을 헤매 듯이 치료하 고 있다고 할 수 있다.

다행스러운 것은 최근 20 30년간 $\mathrm{BPD}$ 를 위한 근거중심 의 치료법에 대한 연구가 활발히 이루어지면서, $\mathrm{BPD}$ 환자들 이 약물치료로 호전되지 않으며 정신치료적 접근이 가장 효 
과적이라는 것이 밝혀지고, $\mathrm{BPD}$ 의 핵심병리를 여러 관점에 서 파악하기 위한 노력의 결실로 다양한 질병모델에 따른 특 수한 치료법들이 개발되었다. 감정조절장애(emotional dysregulation) 모델에 따른 변증법적 행동치료, 애착이론과 정 신화 모델에 바탕을 둔 마음헤아리기 치료, 정신분석이론과 자기 및 대인 기능장애 모델에 바탕을 둔 전이초점치료 등이 그것이다. 이들 치료는 여러 임의대조실험(randomized controlled trial)을 통해 그 효과가 입증이 되었는데, 특히 치료 $3 \sim 6$ 개월째 자살성향, 충동성, 감정불안정성에서 유의한 호 전을 보였다.

그러나 Gunderson과 그 연구진들은 이러한 특수치료만 이 아니라 실제적이고 현실적인 좋은 정신과적 관리만으로 도 비슷한 효과를 낳는다는 것을 여러 연구를 통해 증명했 으며, 더구나 $\mathrm{BPD}$ 의 자연경과 추적조사에서 $85 \%$ 가 치료 없이도 10 년에 걸쳐 관해되었고, 일단 관해된 후에는 재발 하지 않는다는(Gunderson 등 2011, p.210) 결과를 발표하여 경계선 성격장애에 대한 패러다임을 완전히 바꾸는 계기를 마련했다.

$\mathrm{GPM}$ 의 핵심은 진단의 공유와 심리교육이다. 심리교육은 진단 과정을 공개하고 질병의 경과와 예후, 치료 과정을 설명 하고, 실제 생활에서의 어려움에 대해 대인관계 과민감성 모 델을 핵심병인으로 설명한다. 또 약물치료와 입원치료 효과 의 제한점을 설명하여 약물치료 및 입원에 의존하지 않도록 하고, 가족의 참여를 중요하게 다룬다. GPM은 어떤 이론을
바탕에 둔 것이 아니라 임상경험에 의해 확립되었으며, 사례 관리와 비슷하다고 할 수 있다.

연구진들은 $\mathrm{BPD}$ 를 위한 '단계적 관리 모델'을 제안하는데 (p.445), BPD의 경한 초기 단계부터 심각한 단계까지 GPM 과 다른 특수치료들을 유기적으로 통합하여 환자 개개인에 적합한 치료를 시의적절하게 제공하기 위해 고민한 부분이 매우 인상적이다. 또한 이 책에는 $\mathrm{BPD}$ 의 진단평가와 치료를 위해 10세션의 GPM이라는 간단한 관리를 소개하고, 입원 시나 일반 외래에서 $\mathrm{BPD}$ 환자와 가족들에게 이 질환에 대해 설명하는 원고나 바로 활용할 수 있는 치료의 구체적 목표들 을 예시로 보여주고 있다. 역자가 실제로 환자와의 면담에서 활용하고, 리플렛으로 만들어 환자에게 제공하였을 때 환자 와 가족으로부터의 피드백은 예상보다 훨씬 좋았다. 역자는 임상에서 정신치료와 정신분석을 주로 하지만, 특히 중등도 이상의 $\mathrm{BPD}$ 환자들에게는 예비면담 과정 동안 $\mathrm{GPM}$ 의 방식 으로 접근하고 있다. 예비면담 이후에 치료 동기가 있는 경 우, 10 세션의 치료나 정신분석적 정신치료를 GPM과 절충하 여 시행한다. Gunderson과 그 제자들의 말처럼, GPM의 관 점은 역자가 $\mathrm{BPD}$ 를 이해하고 접근하는 관점을 상당히 바꾸 어 놓았다.

이제 Glen O. Gabbard가 이 책을 위해 쓴 서평의 한부분 을 인용하면서 책의 소개를 마치려고 한다. "만약 당신이 경 계선 성격장애를 위한 책으로 딱 한권만 읽겠다고 한다면, 바로 이 책을 읽기를 권합니다." 